\title{
The concept of creating a form-based code of Zelenodolsk
}

\author{
Yulia Zakirova*1, Maria Latypova $^{1}$, and Svetlana Gafurova ${ }^{10000-0001-7636-2268] ~}$ \\ ${ }^{1}$ Kazan State University of Architecture and Engineering, 420043 Kazan, Russia
}

\begin{abstract}
The purpose of the study is to identify and compare territorial zones, volumetric-spatial characteristics of buildings and the peculiarities of the formation of open public spaces in Zelenodolsk. The main results of the study are that a comprehensive urban planning analysis was carried out, on the basis of which the features of the formation of territorial zones in the city were revealed, the boundaries of spatial-environmental morphotypes, their environmental features were identified, and the specificity of the formation of a design code for different areas of the city was determined. The significance of the results obtained for architecture and urban planning lies in the fact that the concept of the form-based code developed in the study for Zelenodolsk can become the basis for updating (or updating) urban planning documents (Local standards for urban planning, General plan, urban planning regulations, City beautification rules). The method of identifying and forming spatial-environmental morphotypes in the city is also of great importance, as the basis for creating a form-based code for Russian small and medium-sized industrial cities.

Keywords. Form-based code, industrial monotown, planning structure, spatial-environmental morphotype, design code.
\end{abstract}

\section{Introduction}

In Russia, a large number of cities were created in the twentieth century during the Soviet period on the wave of industrialization, the post-war restoration of the national economy. The general plans of Soviet cities were formed under the influence of a number of urban planning concepts that suggest certain planning models (linear city, garden city, social city, etc.) and rigid functional zoning. With the change in the political and economic structure of the country, with the adoption of new regulatory and legislative documents, the planning structure of such cities was fixed with new master plans, land use and development rules, and a cadastre. The zoning used in modern urban planning documents of Russian cities is largely based on the functional division of territories. An important task of modern urban planning practice is to improve comfort, scale and identify the individuality of the urban environment. Therefore, today the idea of supplementing functional zoning with a more attentive attitude to the environmental, planning, and semantic features of the building is actively developing. This is the concept of creating form-based area codes. Right now, many industrial cities of Russia are going through the first experience of understanding their planning structure and

${ }^{*}$ Corresponding author: jzakirova@gmail.com 
the need for its transformations in response to the changing demands of the urban community and appropriate planning in strategic and urban planning documents. These changes require making adjustments to urban planning documents. Therefore, the study of the experience of the formation and implementation of the concept of form-based code for many Russian cities becomes especially relevant and timely.

Zelenodolsk is one of the industrial cities of the Republic of Tatarstan, historically planned as a garden city. The city grew out of the working-class settlement Zeleny Dol (1928) on the basis of the earlier settlements of Porat, Kabachishchi, Paratsky Zaton (Paratsk). The settlement received the status of a city in 1932. The population at that time was 7300 people, but by 1939 it had increased to 30200 inhabitants. Since 1958 Zelenodolsk has been the administrative centre of the Zelenodolsk municipal district. Today Zelenodolsk is one of the satellite cities of the Kazan monocentric agglomeration. The population of the Kazan agglomeration is approximately 1.56 million people (data for 2019-2020), the population of the agglomeration core of Kazan is 1257391 people (data for 2020). More than 100 thousand people live in the city of Zelenodolsk, according to 2020, 165915 people live in the Zelenodolsk municipal district (early 2020). The distance to the core of the agglomeration of Kazan, the capital of the Republic of Tatarstan, is about $40 \mathrm{~km}$, time accessibility by private car is 45 minutes, by public transport -60 minutes. The proximity to the capital of a constituent entity of the Russian Federation is undoubtedly a challenge in the socio-economic development of the city, since it imposes the risks of an outflow of the population into the agglomeration core. But at the same time, the relative proximity of major cultural, educational, medical and infrastructural facilities gives the satellite city opportunities for moderately sustainable development. During the period of Soviet industrialization, an industrial city-forming base was created in Zelenodolsk, represented by machine-building production, shipbuilding production, defense industry and woodworking. In the system of the rigidly planned economy of the Soviet period, the city successfully functioned as an industrial settlement. In the 90 s of the twentieth century, due to changes in the political and economic structure of the country, the city of Zelenodolsk (like many small and mediumsized industrial Russian cities) experienced a socio-economic crisis, as a result of which urban production was either stopped or significantly reduced. This led to a significant increase in unemployment. At present, the city is included in the list of single-industry towns of the Russian Federation with the most difficult socio-economic situation (including in connection with the problems of functioning of city-forming enterprises). Today the city participates in the implementation of federal and a number of republican programs aimed at supporting and developing single-industry towns, improving the quality of the urban environment. In the city and the municipal area, activities are being carried out to diversify production and the economy, industry specificity - freight logistics, domestic tourism and recreation.

The purpose of the study is to identify and compare territorial zones, volumetric-spatial characteristics of buildings and the peculiarities of the formation of open public spaces in Zelenodolsk for the development of a form-based code of the city.

Research objectives:

1. To identify the features of the formation of territorial zones in Zelenodolsk;

2. To reveal the spatial-environmental morphotypes in Zelenodolsk;

3. Give recommendations on the formation of a design code based on the environmental, landscape, socio-cultural characteristics of Zelenodolsk.

The planning scheme of the satellite city of Zelenodolsk is based on the concept of a garden city, therefore, in the course of the study, works were considered that study the history and modern development of garden cities, implemented in world practice. The original concept of E. Howard «Garden City» was popular in the theory and practice of Soviet urban planning, but underwent significant transformations (planning and ideological) in Soviet realities. According to E. Howard, a garden city should combine the positive aspects of the 
city and the countryside, eliminating their shortcomings. The environment of such a city would provide residents with the most comfortable and favourable sanitary, ecological and recreational conditions, while maintaining the concentration of public and cultural facilities. The garden city had a fairly rigid centric-circular layout and limiting indicators of the population size ( 32 thousand people), as well as the area of the city (about 240 hectares) and a clear balance of functional zones (only 40 hectares are intended for the urban area, the rest of the territory is used for housing crops, orchards, vegetable gardens, etc.). Initially, in the Soviet theory of settlement, only certain provisions of the concept of a garden city were used, which helped to solve the problems of increasing greenery in the city, ordering manor-type buildings in the suburbs, etc. Then the Soviet concept of garden cities, working garden villages took shape more holistically and independently as a social program for the socialist settlement of the future. The working village-garden itself consisted of standard low- and medium-rise residential buildings, schools, hospitals, markets, kindergartens, etc. Plots were allocated for communal facilities (bathhouse, laundry, garage, etc.). The community centre of the settlement was compositionally highlighted and well connected with all quarters. A typical set of a community centre included a square with a public garden, people's houses, shopping facilities, etc. The working village-garden or city-garden was an extremely green area, including squares, parks, boulevards, green areas of schools, hospitals and children's institutions, as well as an extensive sports and park complex in the central zone of the city. Most of the workers' settlements of this type were founded in the 1920s and 1930s of XX century [1].

We analysed the research devoted to the development of architectural space from the point of view of ecology and green architecture [2-3]. A number of works are devoted to the current trends in the improvement of the ecological situation in cities, including garden cities [4-5]. Researchers note a key role in improving comfort in residential areas, improving people's health [6-7]. The authors considered the work analysing the experience of reorganization of the urban planning structure, infrastructure support, and environmental transformations of industrial cities of a single-industry type [8-10]. We also studied works on the transformation of industrial areas and their flexible integration into the structure of the city [11-12]. The experience of existing approaches to defining the image of a city has been studied [13-14]. In the applied sphere, the image of the city is most noticeably manifested in the branding and formation of the city's design code, thereby influencing the urban economy [15-17]. The work we considered is aimed at studying the transformation of the planning structure of cities [18-20]. The authors also considered the works of Russian researchers on the formation of environmental code and zoning in cities [21-22]. The basics of developing a form-based code in foreign cities are also considered [23-25]. A number of researchers associate the formation of new approaches to urban coding with the priority of the compactness of the city, the concept of smart growth and technologies of smart cities [26-28].

\section{Materials and methods}

The study is based on a comprehensive analysis of the structural and functional structure of the city, environmental and landscape features of the territory of Zelenodolsk and includes the following methods:

- generalization of Russian and foreign experience in the reorganization of industrial cities, the study and systematization of theoretical and literary sources, which made it possible to identify modern trends in the field of urban development of the image of an industrial city;

- field and remote study of the urban environment of Zelenodolsk, collection and study of cartographic materials, which made it possible to collect information for subsequent analysis on individual territories and objects;

- functional-spatial and environmental modeling, which made it possible to present the concept of volume-spatial regulations of Zelenodolsk. 
The materials for the study were documents of territorial, urban planning, strategic planning of the city, the Kazan agglomeration and the Republic of Tatarstan*:

- Strategy of socio-economic development of the Republic of Tatarstan for the period 2030 (developed in 2016).

- Strategy of socio-economic development of Zelenodolsk municipal district for the period of 2030 (developed in 2017).

- Spatial planning scheme for Zelenodolsk municipal district (developed in 2012).

- General plan of Zelenodolsk (developed in 2012, 2018).

- Rules for land use and development of Zelenodolsk (developed in 2020).

Also, the materials for the study were statistical data characterizing the socio-economic and territorial development of the city (Table 1).

Table 1. The balance of the functional use of the territory of the municipality of Zelenodolsk.

\begin{tabular}{|c|l|c|c|c|c|}
\hline \multirow{2}{*}{ № } & \multicolumn{1}{|c|}{ Territory name } & \multicolumn{2}{c|}{2007 year } & \multicolumn{2}{c|}{2017 year } \\
\cline { 3 - 6 } & & hectare & $\mathbf{\%}$ & hectare & $\mathbf{\%}$ \\
\hline \multirow{2}{*}{$\begin{array}{l}\text { The total area of the territory of the municipality } \\
\text { of Zelenodolsk, including: }\end{array}$} & $\mathbf{3 8 2 1 . 6}$ & $\mathbf{1 0 0}$ & 5037.75 & $\mathbf{1 0 0}$ \\
\hline 1.1 & Territories of settlements, including: & $\mathbf{3 8 2 1 . 6}$ & $\mathbf{1 0 0}$ & 3839.43 & $\mathbf{7 6 . 2 1}$ \\
\hline \multirow{2}{*}{ Residential areas } & apartment buildings & $\mathbf{2 4 3 . 8}$ & $\mathbf{6 . 4}$ & 222.88 & $\mathbf{5 . 5 5}$ \\
\cline { 2 - 6 } & manor buildings & $\mathbf{3 4 8 . 4}$ & $\mathbf{9 . 1}$ & 423.3 & $\mathbf{8 . 4 0}$ \\
\hline 1.2 & Public and business areas, including & $\mathbf{1 2 2 . 9}$ & $\mathbf{3 . 2}$ & 147.55 & $\mathbf{2 . 9 3}$ \\
\hline 1.3 & $\begin{array}{l}\text { Industrial zones, zones of engineering and transport } \\
\text { infrastructure, including }\end{array}$ & 546 & $\mathbf{1 4 . 3}$ & 563.75 & $\mathbf{1 1 . 1 9}$ \\
\hline 1.4 & Agricultural use areas & $\mathbf{3 5 3 . 3}$ & $\mathbf{9 . 2}$ & 274.76 & $\mathbf{5 . 4}$ \\
\hline 1.5 & Recreational area & $\mathbf{2 1 0 . 5}$ & $\mathbf{5 . 5}$ & 394.64 & $\mathbf{7 . 8 3}$ \\
\hline \multirow{2}{*}{1.6} & $\begin{array}{l}\text { Special-purpose zone (cemeteries, storage and } \\
\text { disposal of waste, zone of green areas for special } \\
\text { purposes) }\end{array}$ & $\mathbf{4 2 . 6}$ & $\mathbf{1 . 1}$ & 57.36 & $\mathbf{1 . 1 4}$ \\
\hline 1.7 & Zone of restricted areas & - & - & 4.47 & $\mathbf{0 . 0 9}$ \\
\hline 1.8 & Water area & $\mathbf{1 0 5 6 . 9}$ & $\mathbf{2 7 . 7}$ & 966.57 & $\mathbf{1 9 . 1 9}$ \\
\hline 1.9 & Other zones & $\mathbf{1 5 6 . 5}$ & $\mathbf{4 . 1}$ & 727.32 & $\mathbf{1 4 . 4 4}$ \\
\hline & $\begin{array}{l}\text { Territories outside settlements, including } \\
\text { production zones, zones of engineering and } \\
\text { transport infrastructure, recreational purposes, } \\
\text { water area, other zones }\end{array}$ & - & - & 1198.32 & $\mathbf{2 3 . 7 9}$ \\
\hline
\end{tabular}

According to Table 1, it can be noted that the total area of the municipality was increased by 1216.15 hectares, by joining territories outside the settlements. Within the boundaries of the city, the areas of recreational and special-purpose territories have increased.

Table 2. The population of Zelenodolsk.

\begin{tabular}{|c|c|c|c|c|c|c|}
\hline Year & 1995 & 2000 & 2005 & 2010 & 2015 & 2020 \\
\hline Population & 102000 & 100200 & 99216 & 97674 & 98462 & 100039 \\
\hline
\end{tabular}

According to the data in Table 2, we can note the maximum decrease in the population by 3538 people in 2015 and a gradual equalization by 2020 to 100039 people.

"Strategic and territorial planning documents are available on the website of the Federal State Information System for Territorial Planning https://fgistp.economy.gov.ru/ 


\section{Results and discussion}

\subsection{Urban context analysis}

The area of the city is about $37.73 \mathrm{~km}^{2}$, the average population density is 2643.6 people $/ \mathrm{km}^{2}$. In the territorial structure of Zelenodolsk, there are: two planning areas (central and eastern), significantly different in the state of the urban environment, which are located on the upper terrace, relative to the Volga reservoir, and an extensive gray belt formed by a zone of railways, industrial and communal storage zones located on the lower terrace and almost completely overlapping exits to the Volga River. The difference in elevations of the upper and lower terraces is $56 \mathrm{~m}$, which is an additional limiting factor for the accessibility of the coastal zone. The city has a bus station, a railway station, and a seasonal ferry service.

The central region was formed as a working-class settlement-garden. Today it is a wellgreen area of the city with a rectangular block grid with medium- and low-rise buildings, which until recently maintained a balance in the provision of residents with social, cultural, and service facilities. Also in the central area is a city center with administrative buildings, a city market, a hospital campus and a city park. City festivals and events are also held in the Central District. Two spatial connections lead from the central residential area to the industrial zone. These spatial connections are formed by the system of streets leading to two bridges across the railway and leading to the entrance nodes of the two main city-forming enterprises. In 2019, in the central residential area of the city, amid acute social discontent, dozens of lowrise apartment buildings were demolished. Residents of the demolished housing were evicted with minimal monetary compensation. Typical multi-storey residential complexes were built on the territory of the Eastern District to accommodate the townspeople evicted from emergency housing. On the territory of the Central District, a system of large recreational spaces was laid: the Rodina Park, the Avangard city forest park, and the Victory Park. Partial greening of the streets has also been implemented. As a part of the implementation of republican programs aimed at improving the quality of the urban environment, the park areas of the central region and the city beach were reconstructed. The city beach, organized on the western border of the city (border with the Republic of Mari-El), is located on the lower city terrace behind the industrial area and is accessible only to users of individual vehicles.

The eastern region is separated from the central region with a forest, a ravine system and a railway. Active development in this area began in the late 80 s of XX century, together with the creation of a local industrial zone (Zelenodolsk machine-building plant), which is significantly separated from the residential area. In the Eastern District, the planning unit is a «classic» Soviet micro-district, formed by residential buildings of 5-9 floors, 2 kindergartens, a school, and shops within walking distance. To ensure the life of 4 «complete» micro-districts (size 22-24 hectares), a community center, children's and adult polyclinics were also built. The structure of the Eastern residential area also includes individual residential buildings. To date, construction of new housing is being actively carried out on the territory of the Eastern District. However, the entire infrastructural load falls on the already existing social infrastructure (kindergartens, schools, clinics), there are no spaces for recreation and walking. There is almost no landscaped recreational infrastructure on the territory. Green areas are represented by small single public gardens. Therefore, meadows and forests located on the border of the city, approaching the border of the city, experience a strong anthropogenic impact. Today this eastern part of the city exceeds the central region both in area and in population. Over the past 10 years, a swimming pool, an ice complex, a shopping center have been built on the territory. A business center has been reconstructed, and the bus station has been moved. There is still no comfortable exit to the Volga River.

The industrial territorial zone has historically developed and occupies almost the entire lower terrace on the coastal zone of the Kuibyshev reservoir (Volga River). Today, the 
production and communal zone of Zelenodolsk is a territory with low social activity and serves as an impenetrable barrier between the city and the Volga River. The predominant functions are zones of industry (248.6 hectares/41\%) and communal storage facilities (76.8 hectares/12.8\%), individual residential buildings (39.1 hectares/6.5\%), landscaping (104 hectares $/ 17.3 \%$ ). There are sanitary protection zones from industrial and communal storage facilities. The ecological state of the coastal zone is unsatisfactory. According to a comprehensive assessment of the territory in terms of natural and anthropogenic indicators (source: General plan of Zelenodolsk), half of the coastal zone is classified as territories with a critical ecological situation, and there is also a site with a critical ecological situation. Serious remediation measures are required on the projected area due to the problem of untreated wastewater flowing into the Kuibyshev reservoir. Reorganization of trees is necessary, since there are weakened and dead trees. Debris removal and soil rehabilitation measures are required. For the development of the coastal area, it is necessary to modernize industrial and communal storage facilities, with the aim of a more compact location of facilities. It is also necessary to take measures to reduce the sanitary protection zones of promising objects, and for other enterprises to find alternative sites outside the coastal zone for their placement.

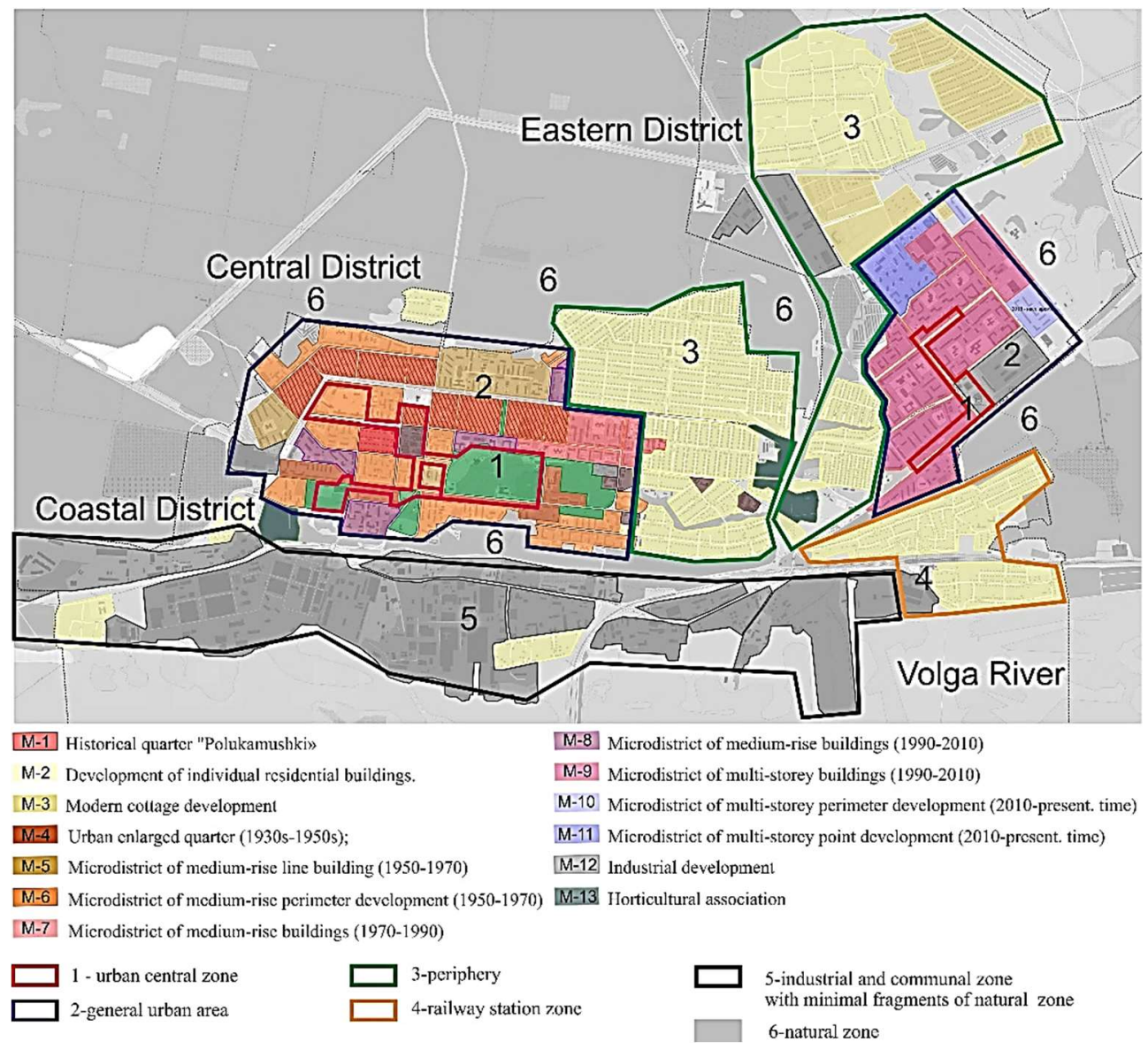

Fig. 1. Scheme of morphotypes of development in Zelenodolsk. 


\subsection{Spatial-environmental morphotypes of Zelenodolsk}

It is proposed to distinguish the spatial-environmental morphotypes of Zelenodolsk by their location in the structure of the city and their role in urban life. It is proposed to distinguish the spatial-environmental morphotypes of Zelenodolsk by their location in the structure of the city and their role in urban life.

At present, the following spatial-environmental morphotypes can be distinguished on the territory of the Central District:

- The urban central zone includes residential buildings with public services (M-6, midrise perimeter buildings of the 1950-1970s), a shopping district («Kolkhozny market»), a special-purpose micro-district («Hospital town») and the main city street (Lenin St.), which is adjoined by city parks and city enlarged quarters of 1930-1950. (M-4) with service and housing. It is proposed to include the historic quarter «Polukamushki» (M-1) in the city's central zone. The reconstruction of this quarter is currently underway. The authors propose to lay the functions of public services and housing on its territory. There is a lack of modern leisure and cultural facilities in the urban central area.

- The general urban area mainly includes residential buildings with preschool, school education and shops within walking distance. The building was formed in different historical periods:

- city enlarged quarters 1930-1950 (M-4),

- micro-districts of mid-rise perimeter (M-5) and lower-case (M-6) buildings 1950-1970,

- micro-districts of mid-rise buildings 1970-1990 (M-7) and the 1990s. (M-8),

Typical type of building 1930-1950 (M-4) is currently being lost and being demolished. However, it was this type of development that shaped the image of a garden city. Today, instead of demolished 2-3-storey buildings, multi-storey residential buildings are being erected locally without additional social infrastructure and the formation of a complex planning solution for the development of the quarter. In this zone it is proposed to form the main boulevard street (Gogol street), connecting the Central and Eastern urban areas. The authors note the need to form a comprehensive plan for the development of the territory where the massive demolition of houses was carried out, as well as the need to develop detailed volumetric-spatial regulations for new buildings.

- The peripheral zone is formed by the development of individual residential buildings (M-2) and gardens (M-13). For this zone, it is necessary to regulate the envelope of development and number of stories, lay down the rules for the improvement of common areas, create public zones of local importance, and also describe the recommended materials, colors and nature of the building.

- Natural zone - forests from the north-west and from the south.

On the territory of the Eastern District, the following spatial-environmental morphotypes are distinguished:

- The central zone was formed spontaneously. It includes key public facilities (bus station, cinema, shopping and business center), residential buildings with built-in service facilities and small retail and service facilities along city streets (Koroleva st., Stolichnaya st., Komarova st.). A comprehensive urban planning reconstruction and landscaping of this zone is proposed. It is also proposed to create a large district park on a ravine-meadow area, which is currently not arranged in a proper way, but is already used for city holidays and sports events.

- The general urban area is formed by mid-rise neighborhoods of the 1980-1990s (M-8), micro-districts of multi-storey buildings in the $1990^{\mathrm{s}}$ (M-9), modern micro-districts of multistorey housing (M-10, M-11). This zone requires the creation of social service facilities, the formation and improvement of common areas (streets, squares, public gardens).

- The peripheral zone is formed by the development of individual residential buildings (M-2) and modern cottage buildings (M-3). For this zone, it is necessary to regulate the building envelopes and number of storeys, develop rules for the improvement of the territory, 
create public zones of local importance, and also develop recommendations on materials, color and nature of the building.

- Natural zone-meadow and ravine areas from the north-east and forests from the south.

At present, the following spatial-environmental morphotypes can be distinguished on the territory of the Coastal District:

- Industrial and communal buildings - these are city-forming enterprises, a railway, communal facilities (M-12). For these objects, it is necessary to carry out modernization and reconstruction, to formulate regulations for the architectural and environmental, natural landscape characteristics and environmental requirements for building. Sanitary and ecological rehabilitation is required on the territory. To make the industrial and communal front more permeable towards the river.

- The station area includes the railway station and the station square (requiring reconstruction and improvement), which are adjoined by individual residential buildings (M-2) and an industrial enterprise (Plywood plant).

- Natural zone - beach (landscaped in 2019, but the territory is removed from the central region by $3 \mathrm{~km}$, from the East by $7 \mathrm{~km}$ ), part of the coastal zone, built up with industrial and communal facilities that restrict access to the territory for residents, part of the coastal zone with fragments of undeveloped landscaping, where it is physically possible to approach the water, but the territory is not well-maintained and is heavily polluted. This zone requires cardinal ecological restoration, cleaning of the river bank and bottom, rehabilitation of tall and shrub vegetation.

On the territory of the Coastal District, it is necessary to form a common urban zone of mixed functional purposes (housing, services and recreation) by modernizing production, removing utility and warehouse facilities and closed industrial enterprises. The development of the road network, public transport routes is required in order to increase the accessibility of the territory.

The next stage in the study can be the development of recommendations for a spaceplanning and environmental solution for each spatial-environmental morphotype. Recommended and standardized parameters include building density, number of storeys, design of facades of buildings of main streets (percentage of glass windows, size of signage, presence of awnings, number of entrance groups), percentage and nature of landscaping of sites, indentation of the building line from red lines, and others.

\subsection{Recommendations for the formation of the design code of Zelenodolsk}

General recommendations for the figurative filling of the design code of Zelenodolsk can be based on the history of the city, landscape and geographical features and the specifics of the city-forming base. The history of the creation of the city associated with the concept of a garden city carries a strong and vivid image. Forests that form the border of the city, the greening system in the Central District, forested gully systems, a variety of tall vegetation, a large water area - these factors indicate the relevance and need for revival, development in new engineering and technical conditions of the idea of a city-park or a city in a super-park. Today, access to the river bank is difficult for residents of the city however the image of the large Russian Volga River has a significant impact on the territorial self-identification of people. This can be seen from the official city symbols, as well as geotags, photographs on social networks, and children's drawings dedicated to urban themes. It is necessary to organize unhindered interaction of city residents with recreational facilities and improve the quality of the urban environment. It is also necessary to preserve and maintain biodiversity in urban conditions, achieve the maximum variety of green urban arrangements, master and develop technologies for «green facades» and green roofs, use environmentally friendly solutions for working with rainwater, drains. The landscape, strengthened by planning techniques, together with landscaped and preserved natural objects (forests and reservoirs) should become tools for 
forming the image of the city. The theme of greenery can also find its reflection in the graphic design of facades, coatings, paving, navigation system, and solution of urban art objects.

It should also be noted that in the primary Soviet idea of a garden city, the rules of landscaping were quite clearly spelled out regulating the parameters of organizing such open urban public spaces as squares and public gardens. In addition, recommendations were formulated on the nature and type of low and medium-rise residential buildings with a characteristic pitched roof, terraced balconies, etc. These characteristic features can still be seen in the authentic urban environment of Zelenodolsk. Some of them have been lost. Some have been demolished as part of the emergency housing liquidation program and are currently being demolished. It is necessary to fix these characteristic parameters of the environment, applying authentic space-planning solutions in the areas of new development. The architectural solution of buildings can be stylized in the design code of the territory, which includes a palette of architectural solutions that forms the volumetric-spatial regulations of the city.

The specifics of the city-forming base associated with mechanical engineering, shipbuilding, woodworking can also become a striking addition to the formation of an urban design system. For residents, this part of their life associated with production is important. Many families have been working in factories for several generations. In conversations with residents, pride in the engineering, technical past and present of the city is shown. But despite this, the production area located on the lower terrace is perceived as something alienated, a gray area, a barrier. It is necessary to change the semantic perception of industrial territories as a category of «terra incognito» into «terra novo» through the organization of objects of attraction for people: sports facilities, modern leisure, culture, food, trade, as well as the construction of housing stock. Industrial aesthetics can manifest itself in the design of public spaces (for example, materials such as wood and welded metal), plastics of small architectural forms, and thematic art objects.

\section{Conclusions}

The study revealed the features of the formation of territorial zones in Zelenodolsk and urban spatial and environmental morphotypes. The method of identifying and forming spatial and environmental morphotypes in a city is of great importance, as the basis for creating a formbased code for Russian small and medium-sized industrial cities. Also, recommendations are given on the formation of a design code based on the environmental, landscape, socio-cultural characteristics of Zelenodolsk. The distinguished spatial and environmental morphotypes and recommendations for creating a design code are given for different planning districts of the city.

The developed concept of a form-based code for the city of Zelenodolsk can become the basis for updating urban planning documents (Local standards for urban planning, General plan, urban planning regulations, City improvement rules). The study made it possible to determine some directions of transformation of the planning structure of Zelenodolsk within the framework of the city-wide and local levels of the city's planning districts, which should be reflected in the updating of the General plan of the city, and in the development of territorial planning projects, respectively. At the city-wide level, the following was highlighted: the formation of spatial links from housing to coastal areas, the creation of natural and recreational zones in the coastal strip, the creation of open leisure and public spaces as buffer zones between urban development and forestry, the revitalization of the development of the entire lower terrace, redevelopment of the production and communal storage zone, freeing up new sites for the development of public and residential functions. For the Central District, the following directions of transforming the planning structure are relevant: the development of a communication network, «green logistics», and the formation of additional nodal spaces with the placement of public and cultural objects in them. For the Eastern District, the following directions of transformations have been identified: the 
formation of a green frame on the territory, the creation of a system of different-scale public spaces, the formation of a public center of the district.

\section{References}

1. M. Meerovich. The concept of a garden city and its transformation in the postrevolutionary period, Sovetskoe gorodostroitelstvo 1917-1941, Progress-Tradition, M., 31-76 (2018).

2. E. Denisenko, S. Novikov, S. Savelyeva, A. Gataullina. Reorganization of public courtyards by using the principles of greening spacein, IOP Materials Science and Engineering 890, (2020). DOI: 10.1088/1757-899X/890/1/012021.

3. E. Shirgir, R. Kheyroddin, M. Behzadfar. Defining urban green infrastructure role in analysis of climate resilience in cities based on landscape ecology principles, Journal of land use mobility and environment 12, 227-247 (2019). DOI: 10.3233/JCC190007.

4. I. Prydko. Green Architecture as a Means of Sustainable Urban Development: Russian and International Experience, MATEC Web of Conferences 193, (2018). DOI: 10.1051/matecconf/201819304015.

5. E. Dorozhkina. Some trends in the formation of recreational spaces in urban development, IOP Conf. Series: Materials Science and Engineering 753, (2020).

6. Z. Tan, K.K.L. Lau, A.C. Roberts, S.T.Y. Chao, E. Ng. Designing Urban Green Spaces for Older Adults in Asian Cities, Int. J. Environ. Res. Public Health. E 16, 4423 (2019). DOI: $10.3390 /$ ijerph16224423.

7. N. Kabisch, M. Van den Bosch, R. Lafortezza. The health benefits of nature-based solutions to urbanization challenges for children and the elderly, Environmental Research 159, 362-373 (2017). DOI: 10.1016/j.envres.2017.08.004.

8. C. Shaimardanova, E. Prokofiev. Principles of organizing new residential development in the peripheral areas of the single-industry towns of the middle Volga, IOP Conf. Series: Materials Science and Engineering 753, (2020).

9. V. Trifonov, O. Loyko, D. Nesteruk, S. Zhironkin, E. Strekovtsova. Managing a monotown as a priority social and economic development area, Youth, Science, Solutions: Ideas and Prospects 1800, 1-5 (2017).

10. G. Baimurzina, E. Kabashova. Features of social and economic development of modern single-industry towns of the Republic of Bashkortostan, Economic and social changes: facts, trends, forecast 1, 106-124 (2020). DOI: 10.15838/esc.2020.1.67.6.

11. A. Mal'tsev, A. Mordvinova. Old industrial areas revitalization: Foreign experience, World Economy and International Relations 63 (7), 40-48 (2019). DOI: 10.20542/01312227-2019-63-7-40-48.

12. A. Lapidus, T. Dmitry. Formation of Methods for Assessing the Effectiveness of Industrial Areas' Renovation Projects, IOP Conf. Series: Materials Science and Engineering 471 (2), (2018). DOI: 10.1088/1757-899X/471/2/022034.

13. A. Krasheninnikov, M. Lazareva, E. Petrovskaya. Local identity framework of built environment, $5^{\text {th }}$ International Multidisciplinary Scientific Conference On Social Sciences And Arts Sgem, Sofia, Bulgaria, (2018).

14. Y. Efremova, O. Goryacheva, R. Kurbanova. Image of a city as a factor of strategic development of a territory, Journal of Environmental Treatment Techniques 7, 925-929 (2019).

15. L. Girard, F. Nocca, A. Gravagnuolo. Matera: City of nature, city of culture, city of regeneration Towards a landscape-based and culture-based urban circular economy, Aestimum 74, 5-42 (2019). 
16. B. Eidelman, O. Bunakov, L. Fakhrutdinova. The main directions of supply chain management development of branding of territories in Russia in modern conditions, International Journal of Supply Chain Management 8 (4), 561-566 (2019).

17. V. Pobirchenko, E. Shutaieva, A. Karlova, E. Polyukhovich. Branding of territories: Approaches to definition, simulation methodology, Journal of Environmental Management and Tourism 10 (6), 1351-1364 (2019).

18. Yu. Arsenteva, E. Zaletova, S. Ismagilova. Structural transformation of small cities, IOP Conf. Series: Materials Science and Engineering 753, (2020).

19. B. Derudder, X. Liu, M. Wang, K. Wu, F. Caset. Measuring polycentric urban development: The importance of accurately determining the «balance» between «centers», Cities 111, (2021). DOI: 10.1016/j.cities.2020.103009.

20. M. Wang. Polycentric urban development and urban amenities: Evidence from Chinese cities, Environment and Planning B: Urban Analytics and City Science 48 (3), 400-416 (2021). DOI: 10.1177/2399808320951205.

21. E. Petrovskaya. Urban planning regulations, environmental codes and criteria for the quality of urban space, Architecture and modern information technologies 2 (39), 268-283 (2017).

22. T. Gudz, I. Karaselnikova, N. Kosolapov. Legal zoning. Regulation of urban development. The experience of Perm, HSE Publishing House, M., (2020).

23. A. Gelabert-Sánchez. Miami 21 form-based code, Miami, Florida, Reflective Planning Practice: Theory, Cases, and Methods, 174-194 (2020). DOI: 10.4324/9780429290275-9.

24. J.B. Kim, B. Balakrishnan, J. Aman. Environmental performance-based community development: A parametric simulation framework for smart growth development in the United States, Proceedings of the $25^{\text {th }}$ International Conference on Computer-Aided Architectural Design Research in Asia 1, 873-882 (2020).

25. K. Onaran. Crafting form-based codes: Resilient design, policy, and regulation, Crafting Form-Based Codes: Resilient Design, Policy, and Regulation 1, 1-148 (2018). DOI: $10.4324 / 9781351203159$.

26. S. Akaraci, M.A. Usman, M.R. Usman, D.J. Ahn. From smart to smarter cities: Bridging the dimensions of technology and urban planning, International Conference on Smart Green Technology in Electrical and Information Systems, 74-78 (2016). DOI: 10.1109/ICSGTEIS.2016.7885770.

27. M.A. Schnabel, Y. Zhang, S. Aydin. Using Parametric Modelling in Form-based Code Design for High-dense Cities, Procedia Engineering 180, 1379-1387 (2017). DOI: 10.1016/j.proeng.2017.04.301.

28. P. Janssen. Evolutionary urbanism, $22^{\text {nd }}$ International Conference on Computer-Aided Architectural Design Research in Asia: Protocols, Flows and Glitches, 303-312 (2017). 